\title{
Robust Decision Making for a Climate- Resilient Development of the Agricultural Sector in Nigeria
}

\author{
Valentina Mereu, Monia Santini, Raffaello Cervigni, Benedicte Augeard, \\ Francesco Bosello, E. Scoccimarro, Donatella Spano, and Riccardo Valentini
}

\begin{abstract}
Adaptation options that work reasonably well across an entire range of potential outcomes are shown to be preferable in a context of deep uncertainty. This is because robust practices that are expected to perform satisfactorily across the full range of possible future conditions, are preferable to those that are the best ones, but just in one specific scenario. Thus, using a Robust Decision Making Approach in Nigerian agriculture may increase resilience to climate change. To illustrate, the expansion of irrigation might be considered as a complementary strategy to conservation techniques and a shift in sowing/planting dates to enhance resilience of agriculture. However, given large capital expenditures, irrigation must consider climate trends and variability. Using historical climate records is insufficient to size capacity and can result in "regrets" when the investment is undersized/oversized, if the climate turns out to be drier/wetter than expected. Rather utilizing multiple climate outcomes to make decisions will decrease "regrets." This chapter summarizes the main results from a study titled "Toward climate-resilient development in Nigeria" funded by the Word Bank (See Cervigni et al. 2013).
\end{abstract}

V. Mereu $(\varangle) \cdot$ D. Spano

Euro-Mediterranean Center on Climate Change, Lecce, Italy

Department of Science for Nature and Environmental Resources, University of Sassari, via Enrico de Nicola, 9, Sassari 07100, DC, Italy

e-mail: valentina.mereu@cmcc.it

M. Santini $\bullet$ F. Bosello $\bullet$ D. Spano $\bullet$ R. Valentini $\bullet$ E. Scoccimarro

Euro-Mediterranean Center on Climate Change, Lecce, Italy

e-mail: enrico.scoccimarro@cmcc.it

R. Cervigni

Environment and Natural Resources Global Practice, Africa Region, The World Bank, Washington, DC, USA

B. Augeard

The French National Agency for Water and Aquatic Environments, Vincennes, France 


\section{Introduction}

The agricultural sector plays a strategic role for the Nigerian economy, as it contributes to more than $40 \%$ of the GDP and accounts for about $65-70 \%$ of employment (Yakubu and Akanegbu 2015). Cereals such as maize, sorghum, millet and rice, and tubers as cassava and yam, account for $70 \%$ of the production of the agricultural sector in 2013 (FAOSTAT; FAO 2015). Cassava and Yam, with a production of about 53 and 40 million tons respectively (FAO 2015), are the leader crops for the Nigerian economy. Cassava, especially, plays an essential role for food security due to its efficiency in producing carbohydrates, its high flexibility with respect to the timing of planting and harvesting, and its tolerance to drought and to poor soils. Maize and Sorghum are currently the most important cereal food crops in Nigeria either in terms of production or in terms of harvested area (FAO 2015). Other important cereals are Millet, mainly cultivated in the north of the country, and Rice, which is cultivated in all of the Agro-Ecological Zones (AEZs) of Nigeria. Rice production has emerged as the fastest growing sub-sector and the most required commodity in the Nigerian food basket.

Rainfed lowland rice is the predominant production system, accounting for nearly $50 \%$ of total rice growing area in Nigeria. Overall, $30 \%$ of the production is rainfed upland rice, while just $16 \%$ is high yielding irrigated rice. Other production systems make up the remaining 4\% (from USAID MARKETS 2009a). Cultivated lands in Nigeria occupied about $44.7 \%$ of land area in 2011, with $37.3 \%$ and $7.4 \%$ consisting of arable lands and permanent crops, respectively (FAO 2015). About two-thirds of the cropped areas are located in the north, with the rest about equally distributed between the center (Middle Belt) and the south. With irrigation accounting for less than $1 \%$ of cultivated area (FAO 2015), the rainfall regime highly affects the national crop production. Cultivation calendars and cropping patterns are different in the north and south, largely reflecting differences in precipitation regimes across the country.

Farming systems are mainly (80-90\%) smallholder-based, with limited access to pesticides, fertilizers, hybrid seeds, irrigation, and other productive resources. Its farming production systems are inefficient, causing a regular shortfall in national domestic production and a need to import food that accounts for about $10 \%$ of overall national imports. Moreover, recent climate patterns (e.g. NIMET's 100-year database or Lebel and Ali 2009) adversely affected national crop production, causing serious implications for food security, public health and the economy of the country. Existing studies on Nigeria (Adejuwon 2005; Odekunle 2004) show that, in general, frequent crop failures and decreases in agricultural productivity are observed as a consequence of climate variability. Nigeria is listed by FAO (AQUASTAT-FAO 2005) among the nations that are technically unable to meet their food needs from rainfed production at a low level of inputs.

In this context, high priority is being posed by Government policies to increase agricultural productivity in order to reduce poverty, increase food security and diversify economy away from oil (NPC 2004; NSSP 2010). One of the options to 
sustain this goal is represented by irrigation development. Given the limited size of effectively irrigated areas, the contribution of irrigated agriculture to total crop production is quite small at $0.9 \%$ and $2.3 \%$ of the total national agricultural production of grains - rice and wheat - and vegetables, respectively. According to the International Commission Irrigation and Drainage $\left(\mathrm{ICID}^{1}\right)$ three main types of irrigation schemes are developed in Nigeria: (i) public irrigation schemes, which are under government control; (ii) the farmer-owned and operated irrigation schemes that receive assistance from government in the form of subsidies and training; and (iii) residual flood plains, where no government aid is supplied, that are based on traditional irrigation practices.

Nigeria is considered one of the African countries with the largest potential for irrigation expansion (World Bank 2010). However, as precipitation highly differs across the AEZs, the potential to improve yields by irrigation is highly variable, and a strategic balance between rainfed and irrigated production has to be achieved to ensure effective management of water resources.

The Nigerian government is pursuing several policies that encourage a viable structure of public and private irrigation with a balanced set of small-, medium- and large-scale irrigated production. In addition to rehabilitation and expansion of existing public schemes, the Master Plan for Irrigation and Dam Development proposes the construction of new dams and irrigation schemes to improve the overall infrastructure of the irrigated sub-sector. About $156 \mathrm{~km}^{3}$ of water is exploitable per year from superficial and groundwater resources; currently, only $5 \%\left(8 \mathrm{~km}^{3}\right)$ is effectively withdrawn (FAO 2016). According to projections made in the National Water Resources Master Plan (NWRMP) produced by the Japan International Cooperation Agency (JICA 1995), incremental water storage of $2 \mathrm{~km}^{3}$ per year will be required between 2012 and 2020 to meet the increasing water demand from the three competing sectors: agriculture (69\%), energy (10\%), and domestic use (21\%).

Since the vulnerability of the agricultural sector to current climate shocks and resource availability is likely to be exacerbated under future environmental change, achieving food, energy and water security in Nigeria will become more and more challenging. Previous works have addressed the analysis of climate change impacts in Sub-Saharan Africa, highlighting high differences in yield projections across different AEZs (Lobell et al. 2008; Seo et al. 2008a; Thornton et al. 2009; Roudier et al. 2011; Webber et al. 2014), due to differences in climate data, emission scenarios and the modelling approach in simulating crop yield (Roudier et al. 2011). The majority of studies are based on a statistical modelling approach (Parry et al. 2004; Lobell et al. 2008; Seo et al. 2008a; Schlenker and Lobell 2010), which however assume stability of the relation between crop and weather. Accordingly, this methodology has a rather limited explanatory power, and is unsuitable for extrapolation outside the range of observed conditions within which it was developed (Challinor et al. 2009; Müller et al. 2011; Rosenzweig et al. 2013).

A minority of studies were conversely based on dynamical simulation of climate change impacts by applying more complex mechanistic process-based crop models.

\footnotetext{
${ }^{1} \mathrm{http}: / /$ www.icid.org/cp_nigeria.html.
} 
These are able to consider both linear and nonlinear crop response to weather variation (Semenov and Porter 1995). According to the available studies, climate change impacts are highly differentiated across specific crops and cropping systems (Mereu et al. 2015; Webber et al. 2014; Roudier et al. 2011), which are characterized by different capacities to adapt to modified climatic conditions and by different strategies implemented to cope with these threats. According to the IPCC AR5 (2014) adaptation strategies for African agriculture can be technological (e.g., stresstolerant crop varieties, irrigation, enhanced observation/monitoring systems) and agronomic adaptation responses (e.g., agroforestry, conservation agriculture). Seo et al. $(2008 \mathrm{~b}, \mathrm{c})$ point out the need for a careful selection of these measures given the specificity of AEZs and the uncertainty related to climate scenarios.

Conservation agriculture and other land, water and crop management practices are "soft" candidates to reduce climate change impacts on crops and improve the sustainability of agricultural systems. Expansion of irrigation is considered as a complementary strategy. Even so, as irrigation entails large costs and upfront investment, it is crucial to size it adequately by selecting the investment strategies that minimize the risk of misjudgments across multiple climate outcomes and reduce regrets.

This chapter proposes a Robust Decision Making Approach (RDMA) to increase the resilience of Nigerian agricultural sector to climate change and variability. It starts from the analysis of the short- to mid-term risks (2020-2050) posed by climate change to the agricultural sector and it is applied to help in reducing the risks of maladaptation (Daron 2015). In other words, it helps decision makers in identifying and choosing the most suitable adaptation options in a context of deep uncertainty, by favoring those options that will work reasonably well across that entire range of potential outcomes. An important point to consider is that the strategies which are robust, i.e. those are expected to perform satisfactorily across the full range of possible future conditions, are preferable to those that are the best ones, but just in one specific scenario, remain highly sensitive to changes, and may perform very poorly under an alternative, but equally probable, scenario (Lempert et al. 2004, 2006; Wilby and Dessai 2010).

Thus, applying RDMA is one way to cope with uncertainty in future outlooks. Other approaches are adaptive management (i.e. selecting a strategy that can be modified to achieve better performance as one learns more about the issues and how the future is unfolding) and scenario planning (comparing how well alternative policy decisions perform under different plausible future conditions). We chose RMDA building based on the comparative work of Lempert and Collins (2007) concluding that it is preferable to adaptive management when, as in the present case, the decision time scales are such that immediate incremental adaptation would not possible when new information becomes available since investments have already been implemented and infrastructure realized. 


\section{Methodological Approach}

Before applying RDMA to support adaptation decisions in irrigation, climate change impacts were quantified using different well-established process based models. Specifically, the analysis includes the following steps and can be represented by the flowchart in Fig. 1:

1. the establishment of a reference development scenario (baseline) that, assuming no-climate change, is the basis for assessing climate change impacts;

2. the definition of a range of possible future climate outcomes to explore the uncertainties related to climate models;

3. the evaluation of climate impacts at the Agro-Ecological Zones (AEZ), watersheds and country-policy level, according to the specific impact investigated;

4. the testing of adaptation strategies and the application of a RDMA to support adaptation decisions in irrigation development.

More details on methods and tools applied are reported in the published report

"Toward climate-resilient development in Nigeria" (Cervigni et al. 2013).

\subsection{Climate Projections and Their Uncertainty}

The high resolution Regional Climate Model (RCM) COSMO-CLM at about $8 \mathrm{~km}^{2}$ of resolution (Rockel et al. 2008) was applied to simulate climate trends from 1971 to 2065 under A1B emission scenario and using the boundary conditions of the General Circulation Model (GCM) CMCC-MED (about $80 \mathrm{~km}$ of horizontal resolution, Scoccimarro et al. 2011). According to the validation with observed climate along the historical period, the RCM was bias-corrected for the whole simulated period (Cervigni et al. 2013 - Chap. 4 and Appendix B).

To take into account the uncertainty on future climate outcomes nine GCMs simulations taking part of the CMIP3 experiment plus those from the CMCC-MED GCM, were used to "perturb" the RCM results along the period 2006-2065 and maintain high resolution. The GCMs chosen for the simulations were thus: HadCM3, CGCM_2.3.2, CNRM_CM3, CSIRO_Mk3.5, CCSM3, MIROC3.2, GFDL_cm2.1, ECHAM5, FGOALS, and CMCC-MED. The approach to perturb RCM outputs using the variability of global simulations (Buishand and Lenderink 2004) was applied to temperature and precipitation fields (Cervigni et al. 2013 - Chap. 4 and Appendix B).

Such climate simulation ensemble was used to drive the impact assessment described herein comparing impact model outcomes in the short and medium term periods (2006-2035 and 2036-2065, respectively), with the historical baseline (1976-2005). According to the multiple components of the analysis, and their dependence on climate variables suffering from different uncertainty degree in the future (e.g. higher for precipitations than for temperature), the full range of models 
Spatial domain

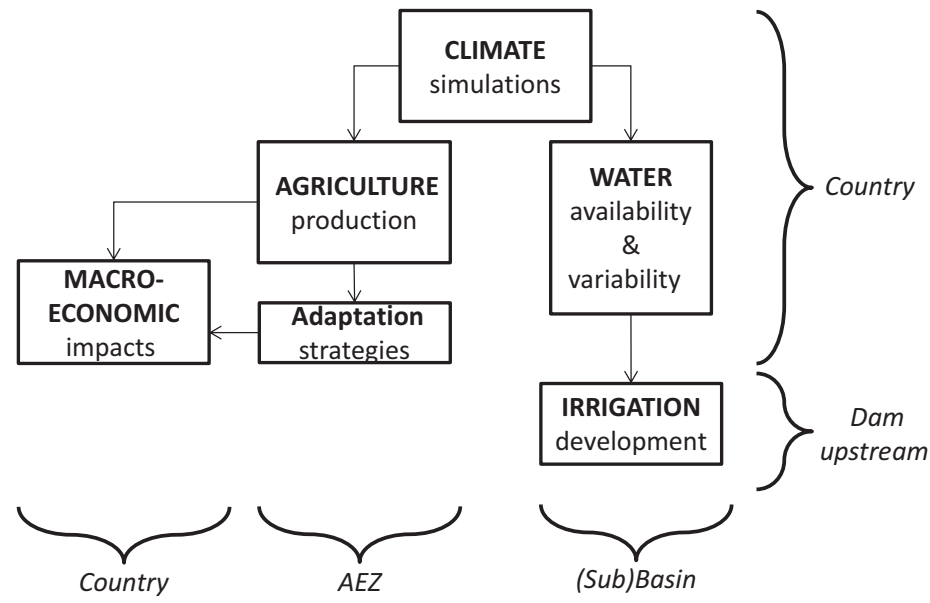

Spatial aggregation of climate-related hazards

Fig. 1 Flowchart of the conducted assessment, and spatial levels (coverage, aggregation) of analysis

(the RCM and the 10 perturbations) or their member suggesting the most extreme impacts were used to well represent the uncertainty range of possible climate outcomes.

\subsection{Crop Modeling: Impacts on Yields}

The software DSSAT-CSM, Decision Support System for Agrotechnology Transfer - Cropping System Model (http://dssat.net/; Jones et al. 2003; Hoogenboom et al. 2012) was applied to analyze the impacts of climate change and possible adaptation strategies for the most important staple food crops in Nigeria: sorghum, millet, maize, rice, cassava and yam. The DSSAT-CSM simulates growth, development and yield of a crop growing on a uniform area of land under prescribed or simulated management as well as the modifications in soil, water, carbon, and nitrogen exchanges that take place under the cropping system over time.

Multiple combinations of soil and climate conditions were considered for the different AEZs of Nigeria (Fig. 2), in which specific crop management options, as growing periods and/or crop varieties cultivated (long or medium growing season) were set according to literature (USAID MARKETS 2009b and 2010; ICS-Nigeria reports). The methodology addresses individual crops, considering crop varieties and management systems representative for each AEZ.

For impact analysis on crop yields, simulation results using a sub-ensemble consisting of RCM simulation and its five most extremes and significant 


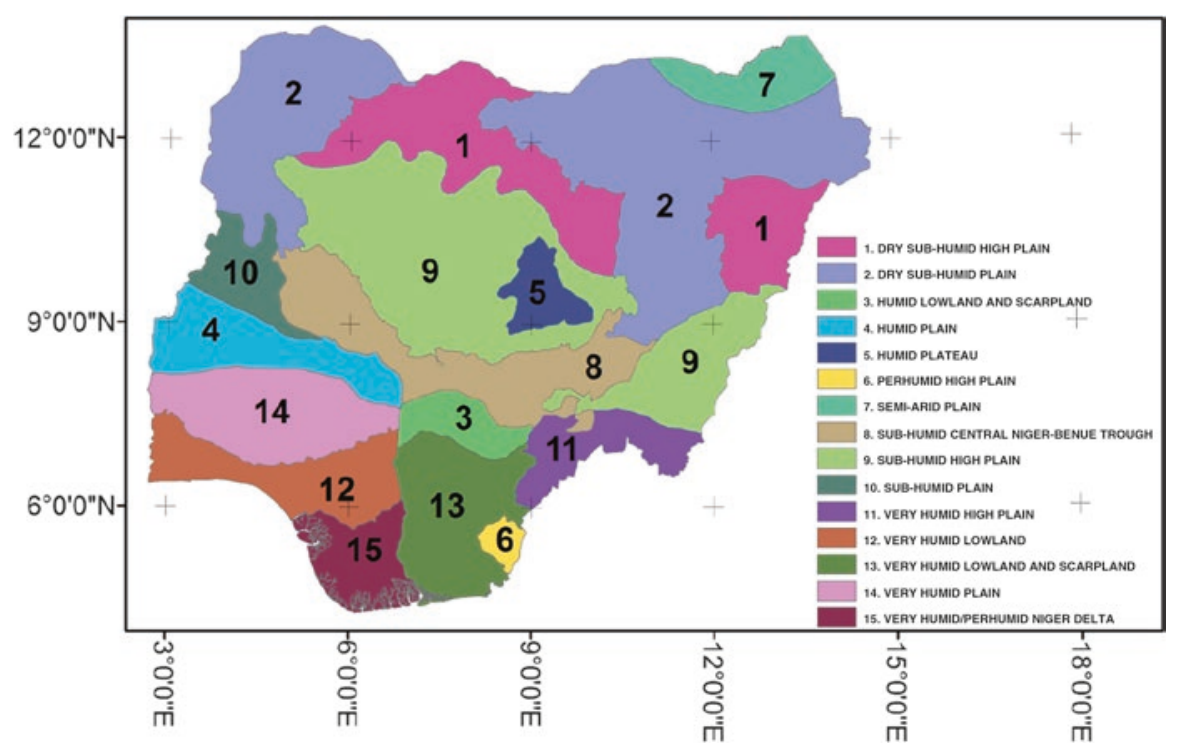

Fig. 2 Map of Agro-Ecological Zones of Nigeria, considered in this study (From Cervigni et al. 2013)

GCM-perturbations, in terms of climate change projections, were used. Simulations were performed assuming both constant $\mathrm{CO}_{2}$ concentration $(380 \mathrm{ppm})$ and transient $\mathrm{CO}_{2}$ concentration (consistent with the A1B emission scenario). Yield was simulated in both rainfed and irrigated conditions.

The climate impact assessment was made by comparing the yields obtained with the weather data for the reference period 1976-2005 (baseline) and those obtainable under future modified climate conditions in the short- and medium-term periods (Cervigni et al. 2013; Chap. 5 and Appendix C).

\subsection{Hydrological Modeling: Impacts on Water Availability}

An analysis on the spatiotemporal availability of water resources for each of the eight Hydrological Areas (HAs) in Nigeria was also conducted in order to estimate irrigation potential at both existing and planned locations (small and large infrastructures) in selected watersheds.

The GIS version of the SWAT model (ArcSWAT) ${ }^{2}$ was applied to evaluate climate risk on water resources. SWAT is a well assessed tool and literature offers good support to its calibration and validation also for the area of interest (Schuol and Abbaspour 2006; Schuol et al. 2008). After modeling the river network through

\footnotetext{
${ }^{2} \mathrm{http}: / /$ swatmodel.tamu.edu/software/arcswat.
} 
the Digital Elevation Model, 893 basins were extracted for the physical-based semidistributed hydrological analysis. Further, layers of 234 soil types, 16 land covers, and 5 slope classes were combined to extract Hydrological Response Units (HRUs), assumed to have similar hydrological response.

Hydrological simulations for each of the 893 basins were made using the full ensemble of climate projections as input. In each site, the RCM simulated inflow during the historical period (baseline 1976-2005) was bias-corrected based on available historical record for the same period. The same set of coefficients was used to correct all the simulated inflows (RCM and its GCM-based perturbations) in the future period of 2006-2065. Outputs were aggregated at 30-year intervals. The short- and medium-term periods were compared with the baseline (Cervigni et al. 2013, Chap. 5 and Appendix F).

\subsection{Macro-economic Analysis}

The effects of climate-induced yield changes on macroeconomic outcomes (e.g. volume and composition of GDP, imports/exports, etc.) were evaluated by inputting into a Computable General Equilibrium model (ICES) the climate change impacts on agricultural production derived from crop yield analysis. A preliminary step was the construction of a future reference scenario, capturing plausible economic development in Nigeria up to the year of 2050 (Table 1).

This reference scenario is the counterfactual "no climate change", on top of which the impacts of climate change on crop productivity were imposed, and against which the consequent GDP and sectoral performance of the economic system were evaluated.

Assumptions for irrigation, consistent with the Master Plan for Irrigation and Dam Development (but delayed by 5 years), are that in 2025 roughly 5\% of Nigerian agriculture (2.1 million hectares) will be irrigated, to reach $25 \%$ of total agricultural land in 2050 (11 million hectares). The assumption made here is that future yields will be, in relative terms, as vulnerable as current ones to climate shocks, so that the deviations from current yields obtained from crop modeling can be applied to future yields as well. The rationale is that yield increases in the reference "no climate change" scenario will be achieved largely through irrigation expansion and through management practices that are suited for current climate, but not necessarily to the warmer and more erratic climate of the future. In particular, it is assumed that the uptake of sustainable land management options will be minimal.

Because of the structure of the Social Accounting Matrix (SAM) used in the ICES model, the disaggregation used for crops and zones is as follows. Rice, cassava and yam are modeled individually; millet, sorghum and maize are modeled as a single aggregated crop class, labeled "other cereal crops". Spatially, six global agro-ecological zones were used for the analysis, finding a correspondence with the ones used for the crop modeling. 
Table 1 Macroeconomic assumptions for the "no climate change" reference scenario

\begin{tabular}{|c|c|c|}
\hline \multirow{2}{*}{\multicolumn{2}{|c|}{$\begin{array}{l}\text { Period } \\
2010-2020\end{array}$}} & Average GDP growth rate $(\%)$ \\
\hline & & 9.0 \\
\hline $2021-2030$ & $2021-2030$ & 8.4 \\
\hline \multicolumn{2}{|l|}{$2031-2040$} & 6.0 \\
\hline \multicolumn{2}{|l|}{$2041-2050$} & 4.3 \\
\hline \multicolumn{2}{|l|}{$2010-2025^{\mathrm{a}}$} & 9.0 \\
\hline \multicolumn{2}{|l|}{$2025-2050^{\mathrm{a}}$} & 5.7 \\
\hline & Vision 20:2020 & Model simulation \\
\hline \multicolumn{3}{|c|}{ A. Sector shares in total value added in 2025} \\
\hline Agriculture & $21 \%$ & $23 \%$ \\
\hline Manufacturing & $18 \%$ & $17 \%$ \\
\hline Mining & $15 \%$ & $21 \%$ \\
\hline Services & $46 \%$ & $39 \%$ \\
\hline \multicolumn{3}{|c|}{ B. Agricultural productivity growth } \\
\hline $2010-18$ & 3-fold & 2.5 -fold \\
\hline $2010-25$ & 6-fold & 5.3-fold \\
\hline $2010-50$ & NA & 19-fold \\
\hline
\end{tabular}

Source: Cervigni et al. (2013)

aThese rates have been calculated assuming that Nigerian Vision 20:2020 objectives (http://www. nationalplanning.gov.ng/index.php/national-plans/nv20-2020) are achieved with 5-year periods

The exercise was performed under different climate simulations, representing the variability of yield changes - and correspondingly of macro-economic impacts across climate outcomes corresponding, on average, to the least and the most pessimistic scenario of yield change (Cervigni et al. 2013, Chap. 5 and Appendix I).

\subsection{Adaptation Strategies in Agriculture}

After the assessment of the impacts on crop yield, a set of select farming practices was tested to analyze their potential to offset, across the different AEZs, time horizons (2020 and 2050) and crops, the negative impacts of climate change on yields (Cervigni et al. 2013, Chap. 6 and Appendix C). These adaptation strategies were selected among the most common and suitable farming practices. For rainfed areas, the shift of the sowing/planting dates, conservation/organic agriculture practices and use of inorganic fertilizers were included in the analysis. For irrigated crops, the analysis focused on yield improvements that could be achieved by modifying planting/sowing dates. 
In the case of the shift in planting date, for each crop, the simulations were conducted adjusting the sowing/planting period 1 month earlier and 1 month later with respect to the traditional cultivation calendar. In terms of conservation agriculture, the analysis focused on nutrient management, and evaluated the use of manure and residues (manure 1 and residues 1) to complement current nutrient provision; or replace them (manure 2). Finally, additional use of inorganic fertilizers was investigated, at a lower (fertilizer 1) and medium intensity (fertilizer 2).

To address climate model uncertainty, climate data from RCM model and two extreme perturbations (NCAR_CCSM3 and GFDL_cm2.1) were considered. The results were analyzed at AEZ and country level. For each crop, only the AEZs where the crops are mostly diffused are considered in the aggregation at Country level.

The approach selected for undertaking the evaluation of the different adaptation strategies is the "regrets" analysis. The "regrets" of adopting each option were expressed as the percent gap in yield improvement between the option being examined and the best performing option under each of the three climate projections; next, the maximum regret was calculated for each option, across the three climate models; and finally, the "mini-max" adaptation option was identified, i.e., for each combination of crop and AEZ, as the one that minimizes the maximum regrets across climate models.

Successively, an evolution (in 2020 and 2050) of cropping patterns at the level of AEZs was defined using information from the macro-economic model. Moreover, the land area to which the "mini-max" adaptation options should be applied to eliminate as much as possible of the "production gap" between the reference and three climate change scenarios were evaluated.

\subsection{Costs of Adaptation Options}

As an additional experiment, the aggregate costs and benefits of the adaptation strategies identified were explored to investigate if they could be worthwhile in economic terms (Cervigni et al. 2013; Chap. 6). Costs include the direct outlays associated to expanding irrigation and promoting improved farming practices in rainfed areas. In addition to direct outlays, there are also opportunity costs of diverting productive capital, which in the absence of climate change would have been allocated to other development priorities. The benefits are given by the value of the additional output that can be produced once the adaptation measures are in place.

To evaluate the net effect, the macro-economic model was run without negative climate change impacts on yields, as these effects are fully offset by adaptation. At the same time, the model run included a decrease in the annual capital stock, in an amount given by the extra expenditure on adaptation. The metric used to assess the net effect is the terminal value of GDP in 2050, with adaptation, and without. 


\subsection{RDMA for Irrigation Infrastructures}

When moving attention to the adaptation strategies for irrigation, it is crucial to consider that uncertainty in future precipitation makes it difficult to project how much water will be available in the future for storage. In case of a changing climate, a given storage design based on historical data can receive less/more water than expected and produce less/more benefit than projected. Climate change impact must therefore be considered in the design of new projects of water storages and irrigation infrastructure development, in order to minimize under- or over-design.

RDMA guiding the selection and design of future irrigation schemes can allow a decision maker to:

1. prioritize the schemes where the area of overdesign risk is smaller than the area of missed opportunity;

2. extend the irrigation area design if the risk of missed opportunity is large; and

3. design the storage facilities conservatively or favor crops that are less sensitive to failures of water supply if the area of overdesign risk is large. Adapting the design to a future climate change has a certain adaptation cost, which is the extra capital cost of building storage or irrigated area; the cost becomes negative if less storage or area is built compared to the historical climate. The benefit is the extra revenue obtained from selling more irrigated crops.

To evaluate what investment decisions on irrigation development are robust under a wide range of climatic outcomes, hydrological modeling results have been used to illustrate the practicability of RDMA for planning irrigation development (Cervigni et al. 2013; Chap. 6 and Appendix J).

The study focused on 18 planned dam sites to identify design options that could minimizes the regrets over a range of possible future climate outlooks. The regrets are defined as the difference in economic return between the chosen option ("no foresight") and the best possible option calculated for each scenario ("perfect foresight"). The Net Present Value (NPV) is the metric used to estimate the value of the different investment decisions.

Monthly data inflows from the hydrological analysis at dam level allowed calculating storage-yield curves (SYCs) for the respective upstream basin, indicating the firm basin yield produced from a given level of storage or, alternatively, storage capacity needed to provide a given basin yield. SYCs were built according to the Sequent Peak Algorithm (SPA; Thomas and Burden 1963) designed for studying reservoir capacity.

The analysis was based on a comparison between SYC referring to the baseline (1976-2005), and 30-year future periods (2006-2035 and 2036-2065), simulated under the whole ensemble of climate projections. Changes in the SYCs for the future simulated flows show the combined effect of predicted changes in flow magnitude and inter-annual variability. 
The optimization was carried out with respect to two decision variables: the amount of stored water and the irrigated area. Then, if the purpose of the dam is to irrigate a targeted area, the decision should be made on the amount of storage. If the dam is already built or there are constraints on the storage size, the decision should be made with regard to the irrigated area.

Eleven "perfect foresight" storages were calculated to generate enough yield to provide water to the irrigated area under each climate scenario. Then, the storage of the "no-foresight" case (under current climate) is used to estimate the area for irrigation under each scenario. The difference in storage cost and irrigation revenues between the "perfect foresight" case and the "no-foresight" case corresponds to the regrets. The robust storage option is obtained by adjusting the storage of the "noforesight" storage in order to minimize the average and the maximum regrets under all climate scenarios. Robust decision making on irrigated area can be estimated following a similar method, but the storage is assumed to be fixed, while the irrigated area is optimized to minimize regrets.

The case study sites were selected in accordance to Government plans to develop irrigation, as reflected in the Master Plan for Irrigation and Dam Development (2009-2020); and using the following criteria: (i) the main basins where new irrigation development is planned should be represented; (ii) the number of sites in each HA should be proportional to the area planned for irrigation development in the HA; (iii) catchment size should be larger than $100 \mathrm{~km}^{3}$ (so that sub-basins are representative of the whole catchment behavior); (iv) lack of dam upstream; and (v) dry and wet future climates should be represented. A small-scale irrigation dam in the northern dry HA was added. The analysis purports to illustrate the policy significance of the RDM approach but should not be considered as an assessment of the technical or financial feasibility of the design solutions investigated, which would require more detailed investigation.

\section{Results and Discussion}

\subsection{Climate Projections and Their Uncertainty}

The simulated air surface temperature averaged over Nigeria shows a strong increasing trend up to $1-2{ }^{\circ} \mathrm{C}$ in 2050 compared to the present average temperature, with the highest increases in the North. In the short-term future (2020), the entire country is predicted to experience a moderate surface air temperature increase.

The precipitation time series averaged over Nigeria for the period of 19762065 shows no significant trends associated to most of GCM-based perturbations; only the data perturbed through the GFDL model shows a significant negative trend. The model results for precipitation were summarized by defining 
four classes of risk/conditions at hydrographic sub-basin level: wetting risk, drying risk, stable, uncertain. A given sub-basin is considered "stable" if most climate models (i.e. those falling within the range of the 1st to the 99th percentiles of the ensemble) agree that future rainfall will not be larger (smaller) than $15 \%(-15 \%)$ of historical values. Sub-basins are considered exposed to "dry risks" if the 1 st percentile is less than $-15 \%$ and the 99 th percentile if less than $15 \%$, to "wet risk" when the 99th percentile of changes is larger than $15 \%$ but the 1 st percentile is more than $-15 \%$; and are considered uncertain when both a decline larger than $-15 \%$ and an increase larger than $15 \%$ are considered possible.

Cervigni et al. (2013, Chap. 4 - Map 4.2) found that around 2020, 53\% of the country's area is expected to be under wetter conditions, $10 \%$ under lower rain availability, $35 \%$ stable, and the remaining $2 \%$ present high uncertainty across precipitation projections. In 2050, $41 \%$ of the country is projected to be under wetter conditions $14 \%$ under drier conditions, $20 \%$ stable, and the area subject to uncertainty increases to $25 \%$. More evident clusters of drying areas in the short- and medium-term are concentrated in the SE plateau and along the SW littoral, the stable areas in the center and along the central and eastern coastal zones, wetting areas in the north with evident uncertainty mainly in the mediumterm period.

\subsection{Impact Analysis on Crop Yields}

Climate change impacts on crop yields are expected to be considerably variable over AEZs and crop types. The differences among crops are related to the specific crop sensitivity to modified climatic conditions as well as to crop spatial distribution and crop calendars. The impacts tend to increase from short- to medium-term period. Results are aggregated across AEZs, to develop impacts at the level of individual crops, and across crops, to produce results at the level of AEZs, using baseyear information on production shares and value added to define weights used for aggregating. Only the results based in a fixed $\mathrm{CO}_{2}$ concentration are reported here. The full set of results, including increases in $\mathrm{CO}_{2}$ atmosphere concentration, is reported in Cervigni et al. (2013).

In terms of impacts at the level of crops, the results show medium term (2050) yield reductions, with negative median values for all crops in 2050 (Fig. 3b). However, yam, millet and cassava exhibit uncertainty, particularly in 2020 (Fig. 3a), where the median across climate models indicate the possibility of moderate yield increases (in the order of 3-6\% or less). In 2050, the consensus across models is higher, with $70 \%$ of the model pointing to a decrease in yields. Rice appears to be the most vulnerable crop in both periods, with yield decline of $7 \%$ in 2020 and $25 \%$ in 2050 . 


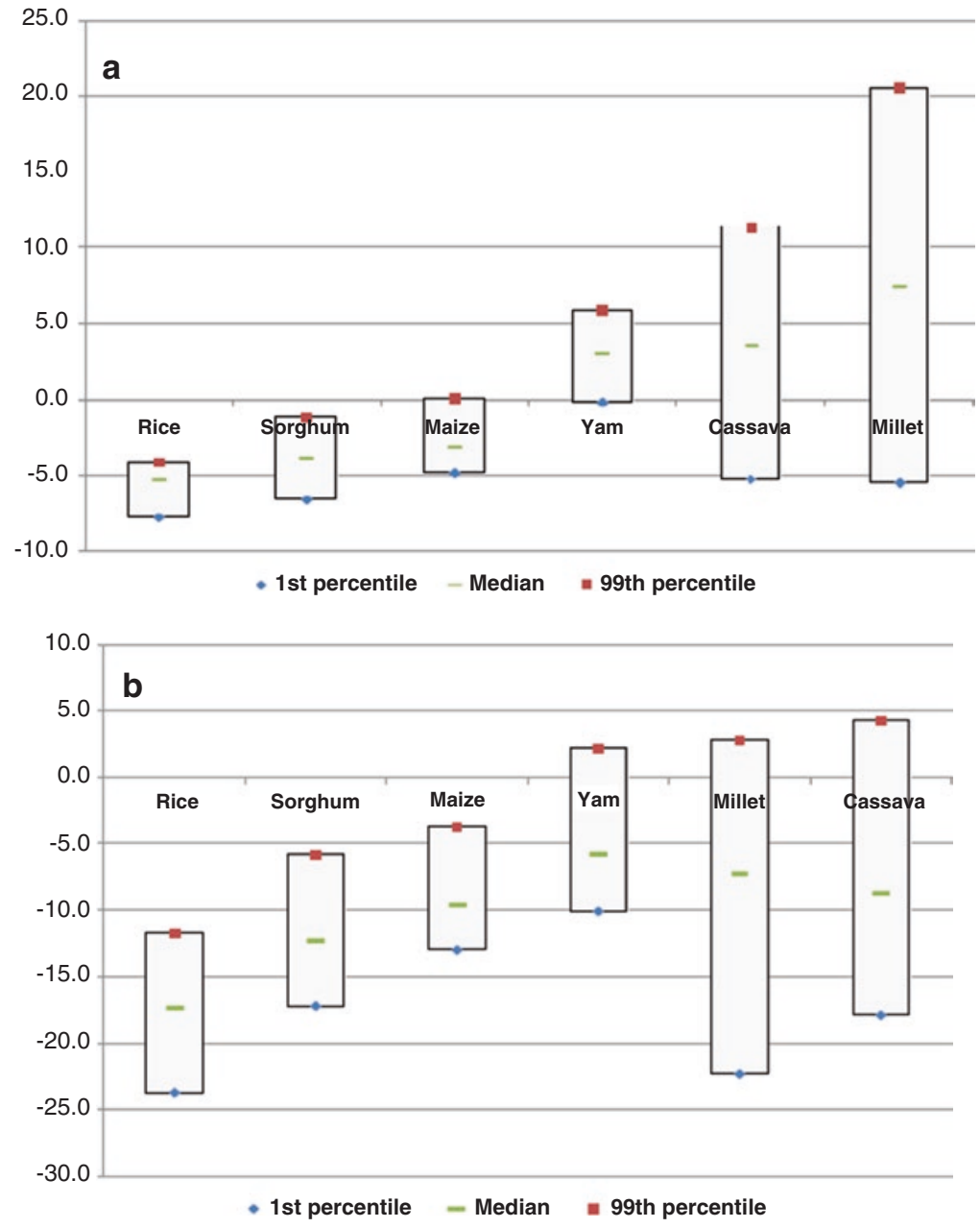

Fig. 3 Aggregate percent change in crop yields for 2020 (a) and 2050 (b) (From Cervigni et al. 2013)

Temperature change is likely to be the major driver of yield shocks, rather than water content (this is consistent with other studies such as Lobell et al. 2008 and Lobell and Burke 2010), particularly in presence of less clear signals of precipitation changes. Temperature increase affects crop growth by shortening the crop-growing period and reducing the amount of biomass accumulation. This produces a decrease in crop yield, even if crops are not under water stress conditions. 

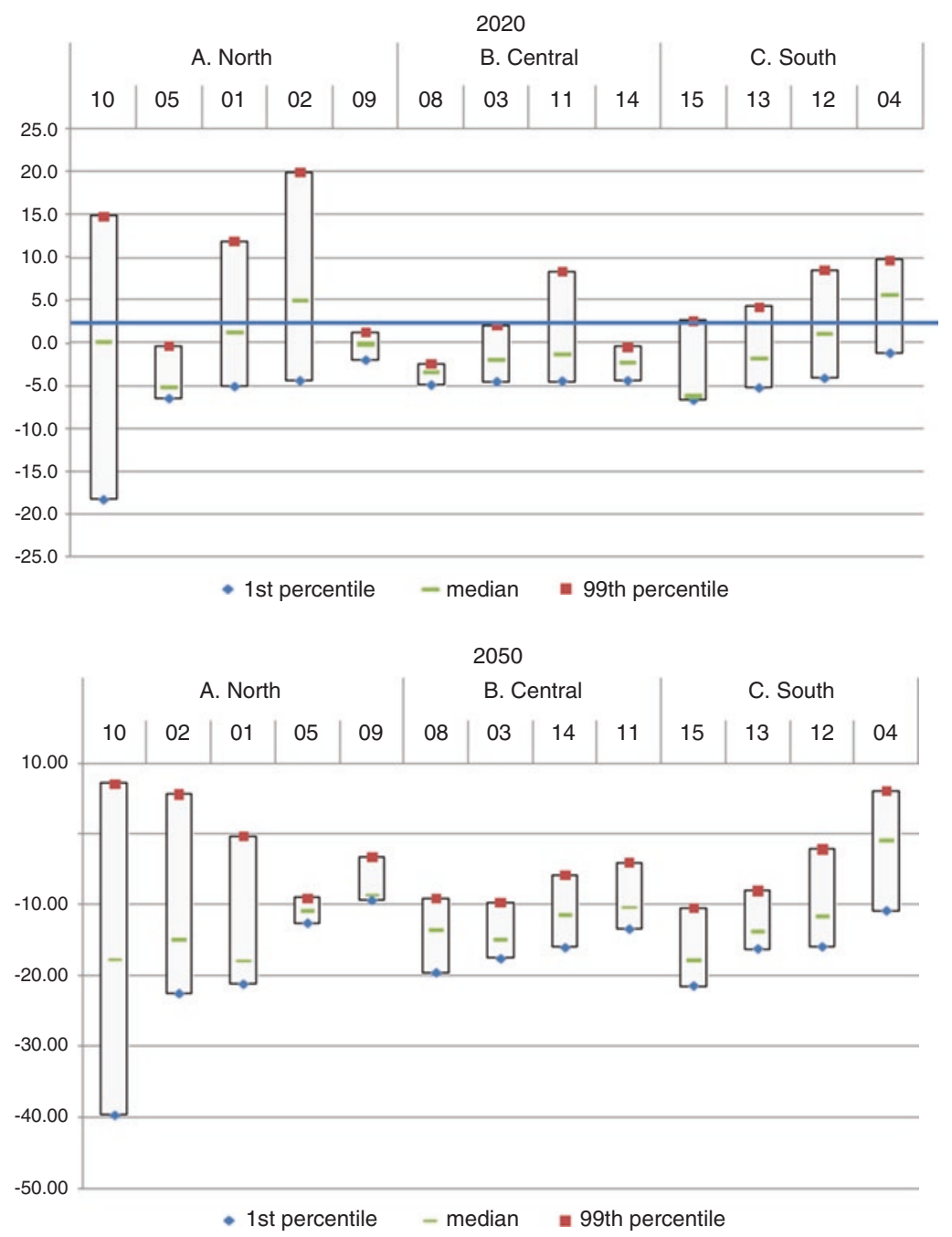

Fig. 4 Aggregate percent change in crop yields by AEZ (2020 and 2050) (From Cervigni et al. 2013)

In terms of impacts at the AEZ level, the Northern area (Fig. 3) appears more subject to risks of large declines (close to $20 \%$ and $40 \%$ in 2020 and 2050, respectively), but shows also larger uncertainty. Despite the significant amount of variability across space, by 2050 the likelihood of aggregate yield decline appears stronger in all zones, as indicated by the negative median values observed in Fig. 4. 


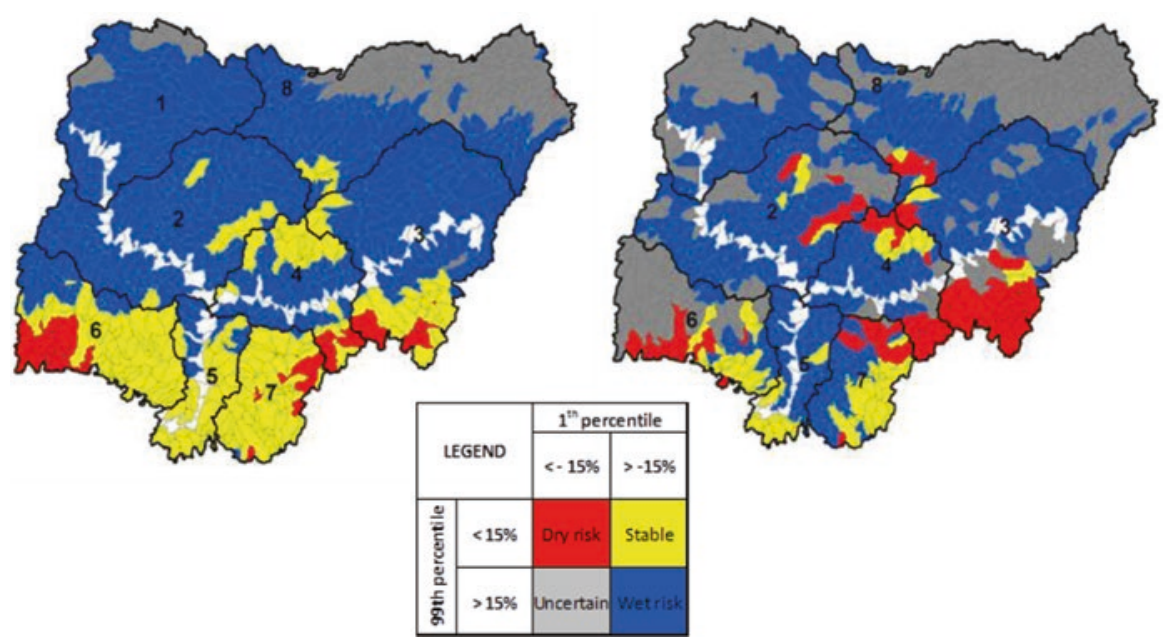

Fig. 5 Distribution of classes of risk for water flows in 2020 and 2050 vs. 1990. Discretized spatial units are hydrographic sub-basins, while numbered units are Hydrological Areas (From Cervigni et al. 2013)

\subsection{Water Availability Impact Analysis}

The hydrological modeling tools were used to convert changes in climate variables (temperature, precipitation) into changes in water flows, and thus changes in water potentially available for storage to sustain multiple uses. Using the same risk classes defined for the analysis of rainfall changes to summarize the consensus among climate models, it was found (Fig. 5) that, by 2020,62\% of the country is expected to be under wetter conditions, $4 \%$ under dry risks, $23 \%$ stable, and the remaining $11 \%$ are characterized by uncertainty. In 2050 , there is still a significant part of the country projected to become wetter (although decreasing from $62 \%$ to $49 \%$ of land areas); the share of areas under dry risks increases from $4 \%$ to $10 \%$ (accounting however for $17 \%$ of historical runoff). The share of stable sub-basins decreases to $8 \%$ of total land areas; while uncertainty increases considerably to $33 \%$ of the total.

It is noteworthy that there is a high uncertainty for the arid/hyper-arid regions in the northeast. Except for the central high plateau, the majority of the central and northern parts of Nigeria are expected to experiences an increasing availability of water resources, although the uncertainty for 2050 is more pronounced. The results for central area, SE mountains, and SW littoral indicate a general drying trend in the short and medium-term. Further, while flow is projected to increase up to $200 \%$ in some cases, the weighted average of increases is only about $33 \%$, because the larg- 
est increases of flow are projected to take place in relatively drier basins. It is only for basins in the bottom $30 \%$ of the flow distribution that flow is projected to increase by more than $30 \%$. These changes in water flows are likely to have significant effects on the reliability of irrigation systems, which is determined by magnitude (average) and variability of inflow.

\subsection{Macro-economic Impacts}

The crop model analysis projects a decline in crop production, growing with time and particularly significant by 2050 for the "other cereals" aggregated class, which, unlike the other crops, is in the order of $9.6 \%$ even in the most optimistic climate scenario. Low case scenario declines are high also for Rice $(-8 \%)$. Overall, the outcomes project: (i) an increase in domestic crop prices (particularly severe in the case of rice) suggesting a more rigid demand, and (ii) significant changes in food trade patterns, with net imports increasing in the case of rice and the "cereal crops" to offset the projected decline in domestic production.

Rice and cereals constitute the large majority of agricultural imports in Nigeria in the baseline (35\% rice and $46 \%$ cereals in 2050). Accordingly, the general equilibrium adjustment to the overall decline in production (occurring for all crops in 2050) consists in meeting demand where possible via an increase in imports, which is higher for crops with relatively lower import prices in the baseline (such as rice and other cereals). The combined effect of changes in production, prices and imports turns into an overall reduction in GDP compared to the no-climate change reference scenario, which by 2050 varies between $3 \%$ and $4.5 \%$ (Fig. 6), depending on the climate model. These results should probably be considered as a conservative, lower bound estimate of macro-economic impacts of climate change.

\subsection{Adaptation Options in the Agriculture and Water Sectors}

It is likely that an efficient adaptation strategy for the agricultural sector in Nigeria requires a combination of expansion in irrigated areas and improved management practices for rainfed crops, allocated accorded to the considerations discussed in this paper. Several factors will contribute to determining the ultimate outcome, including relative costs, resource availability, the institutional context, etc. This section presents analyses of options that can be deployed in rainfed areas and to what extent they could counter the overall impact of climate change on production, and at what cost. 


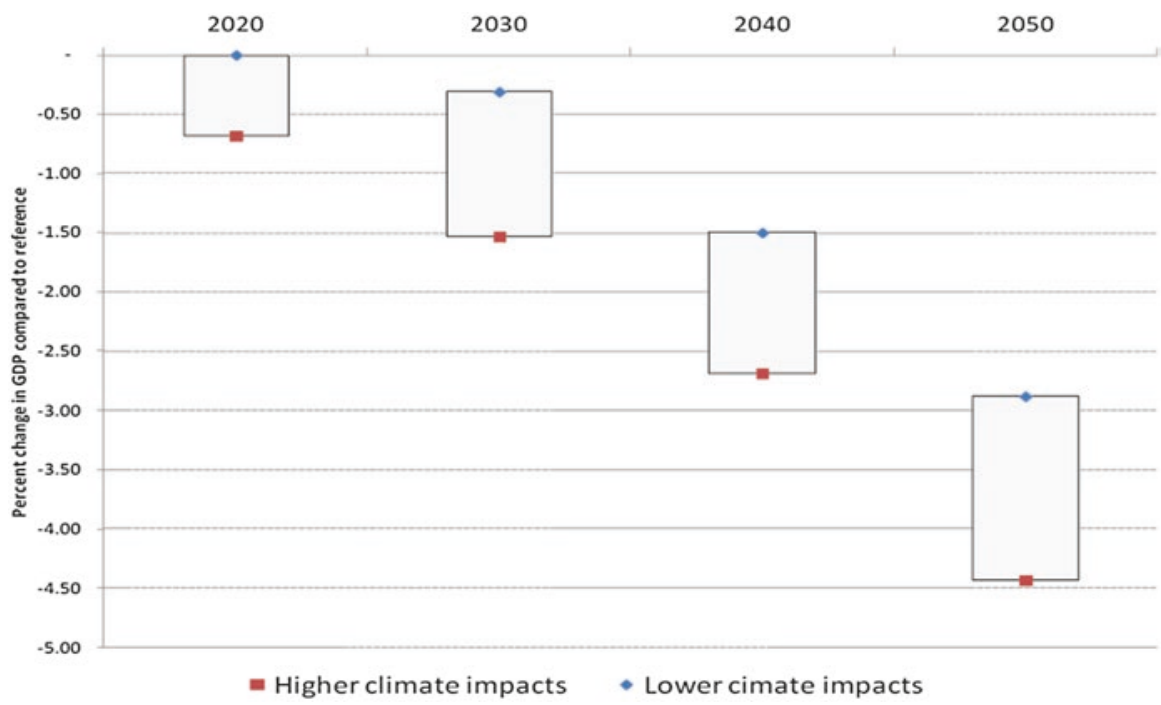

Fig. 6 Deviation of GDP from the no-climate change reference scenario (From Cervigni et al. 2013)

\subsubsection{Adaptation Through Sustainable Land Management Practices}

The adaptation options tested (Table 2) appear to perform well, both in the shortterm (2020) and medium-term (2050), improving yields (compared to a noadaptation case) from $20 \%$ (e.g. changes in sowing/planting dates) to $90 \%$ (e.g. residues and other nutrient management options) of the cases, depending on crop, time horizon, climate model and AEZ considered (Figs. 7 and 8).

The use of residues and "manure 1", at worst, performs slightly less than the noadaptation case; in the best cases, they deliver yields $30 \%$ higher. Change in planting dates can produce significant improvements (in excess of 20\%), but in some crops and zones they can actually result in a further yield decline. The wide range of variability in the performance of the options points to the need of further evaluating the suitability of different adaptation options to different crops and AEZs under conditions of climate uncertainty.

Results of the regret analysis (Fig. 9) shows that "Manure 2", "Manure 1" and "Residues" are the best performing options, accounting for $75 \%$ of total mini-max options. It is important to note that besides increasing nutrient availability, these options increase soil fertility in a broader sense: through improvement of soil characteristics, of soil water retention and thus availability; and through reducing nutrient losses by runoff and leaching.

The optimal mix of adaptation options is highly crop- and location-specific (Fig. 10): e.g., the mini-max strategy for Cassava is "Manure 2" in $90 \%$ and "Manure 1 " in $10 \%$ of the AEZs; while in the case of Rice, the strategy is to adopt "Manure 1 " in $75 \%$, "Fertilizer 2" in $17 \%$, and "Residues" in $8 \%$ of the AEZs. 


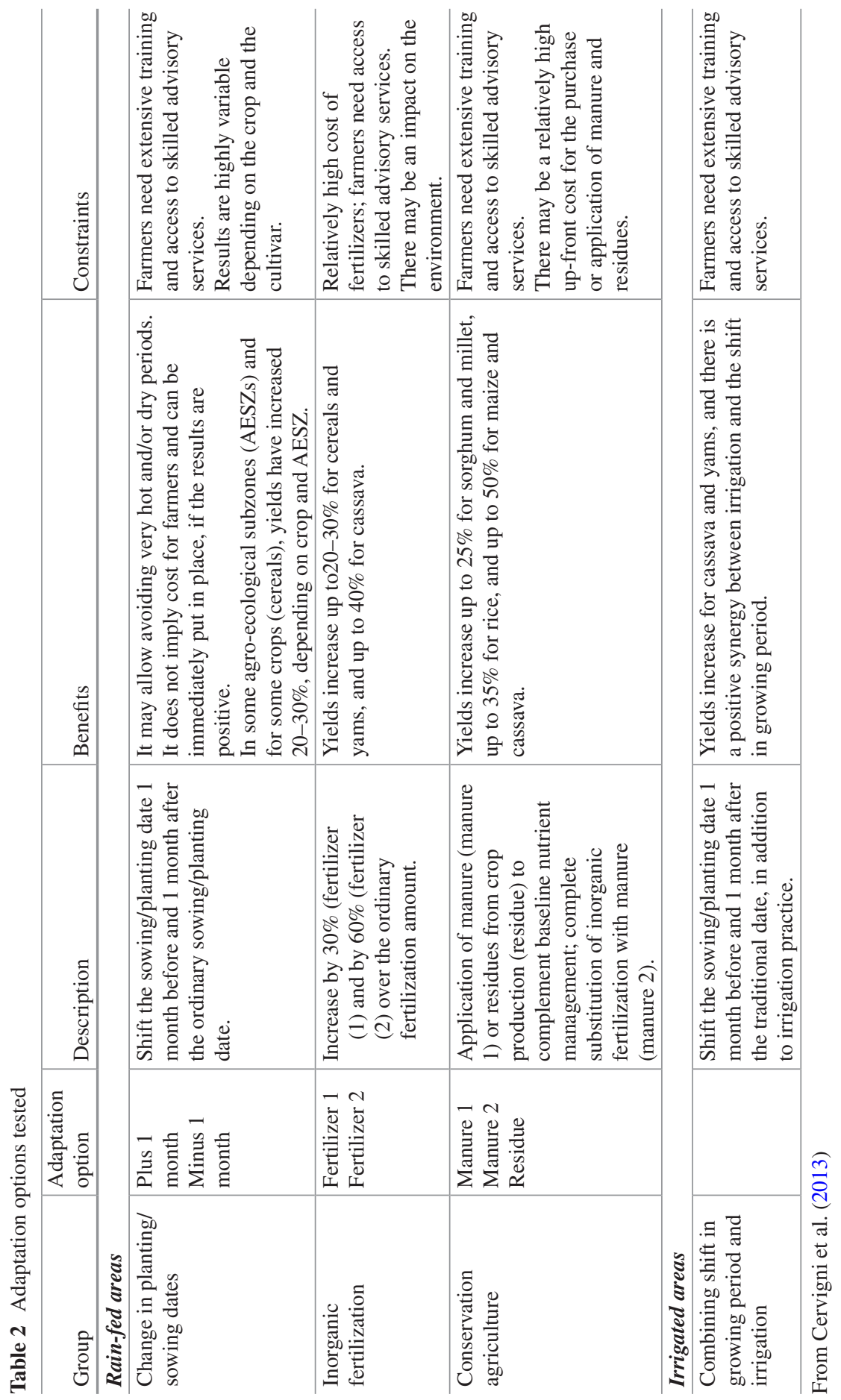




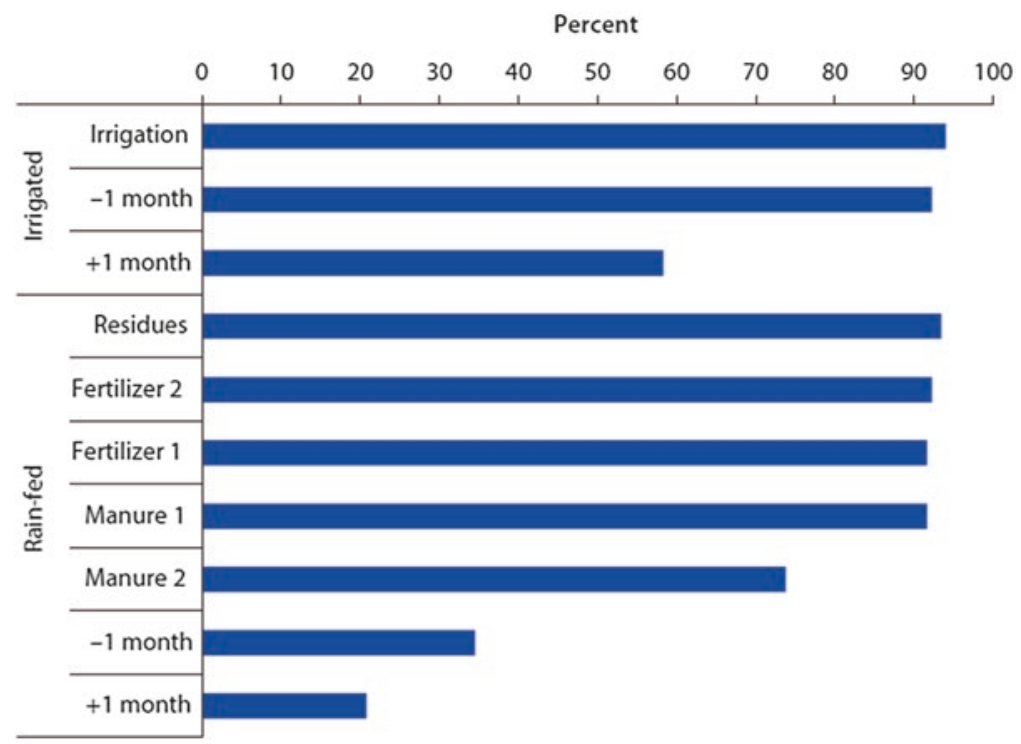

Fig. 7 Safety ratio of the adaptation options 2020 (From Cervigni et al. 2013)

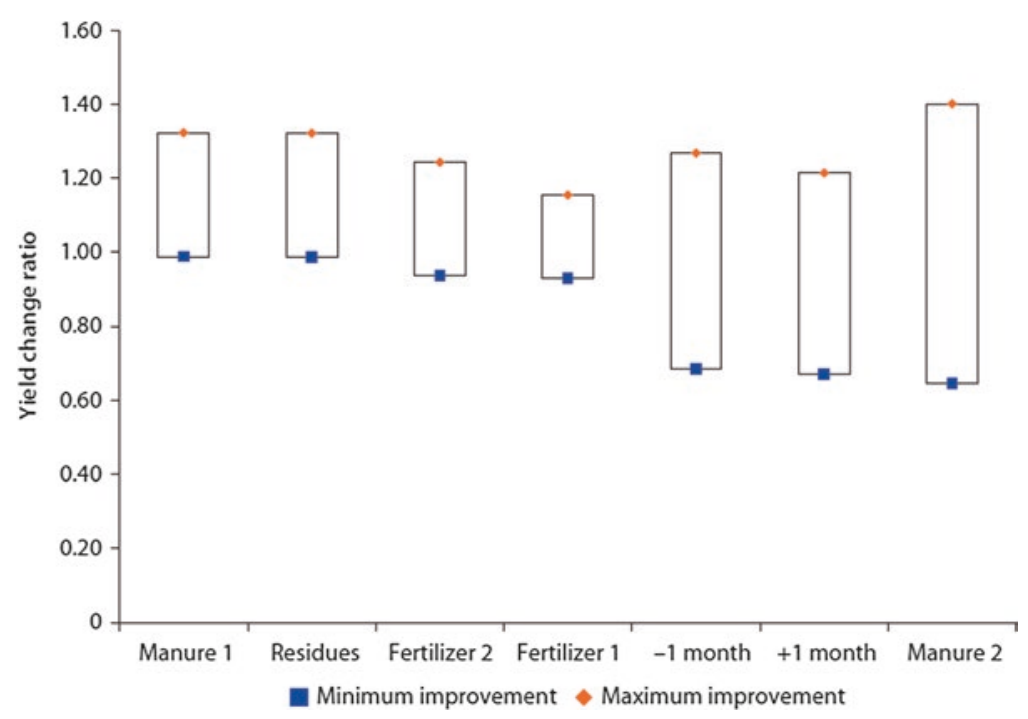

Fig. 8 Adaptation options: maximum and minimum yield improvement (From Cervigni et al. 2013) 


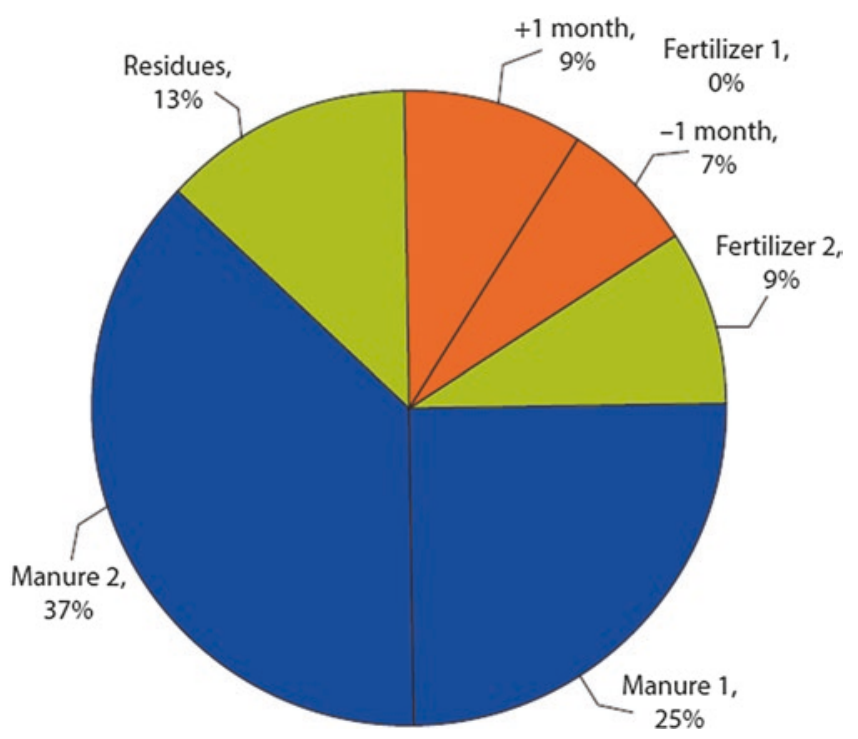

Fig. 9 Mini-max adaptation options for rainfed areas (From Cervigni et al. 2013)

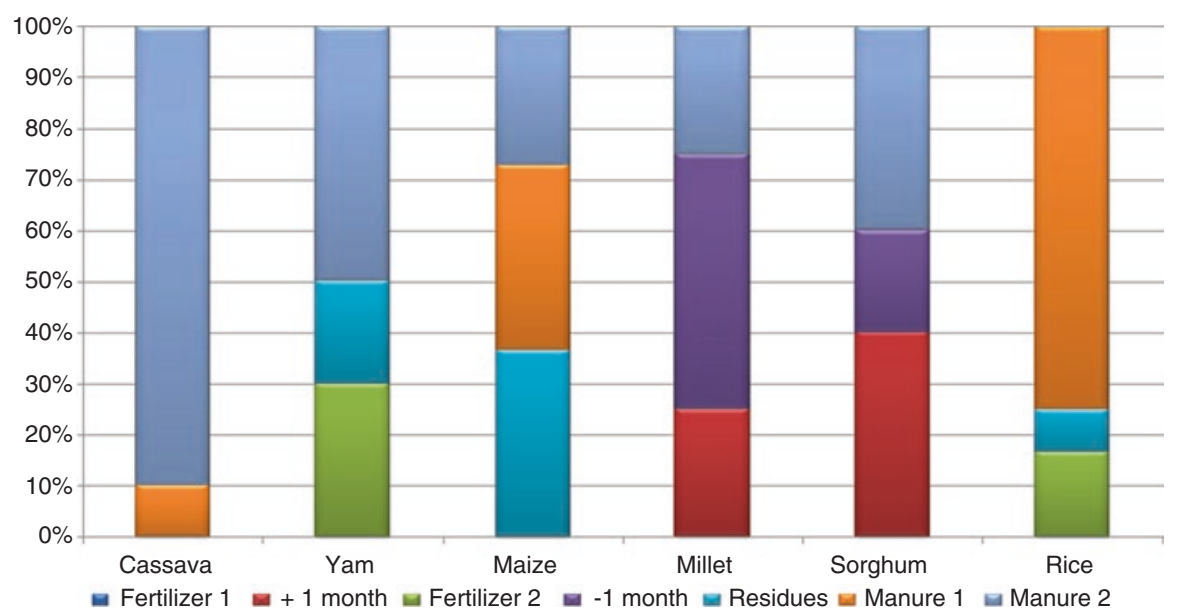

Fig. 10 Composition of mini-max adaptation strategies across rainfed crops (From Cervigni et al. 2013) 
Similarly, at the level of AEZ (Fig. 11), the mini-max adaptation strategy in AEZ 10 entails the adoption of a single option, namely "manure 1", whereas in the case of AEZ 11, the strategy includes five options, namely "-1 month", "+ 1 month", "Fertilizer 2", "Residues", and "Manure 2". These findings highlight the importance of stepping up research, development and extension services, to enable the identification and deployment of crop- and location-specific adaptation options.

Our analysis (Table 3) finds that by 2020 adaptation should be applied to a total of 0.6 to 1.1 million hectares (depending on the climate model considered); by 2050, due to more severe climate impacts, the area should increase to 14-18 million hectares. While in 2020 the mini-max adaptation options succeed (with the exception of millet in one climate model) in fully offsetting climate impacts, a residual gap remains in 2050, ranging from $1 \%$ to $22 \%$, depending on crops and climate models (Table 4). Taking into account the yield differential over time between rainfed and irrigated conditions, the remaining production gap could be filled by expanding irrigation in the medium term (2050) to between 1.5 and 1.7 million hectares (Table 5).

\subsubsection{Costs of Adaptation}

Our results (Table 6) also indicate that adaptation is effective at reducing the net GDP loss, provided that unit costs can be kept in check.

In the "low unit cost" case, the terminal year loss in GDP is always lower with adaptation than without; the benefit-cost ratio of adaptation ranges between 1.2 to almost 2. However, under the high unit cost case, the proposed adaptation strategy

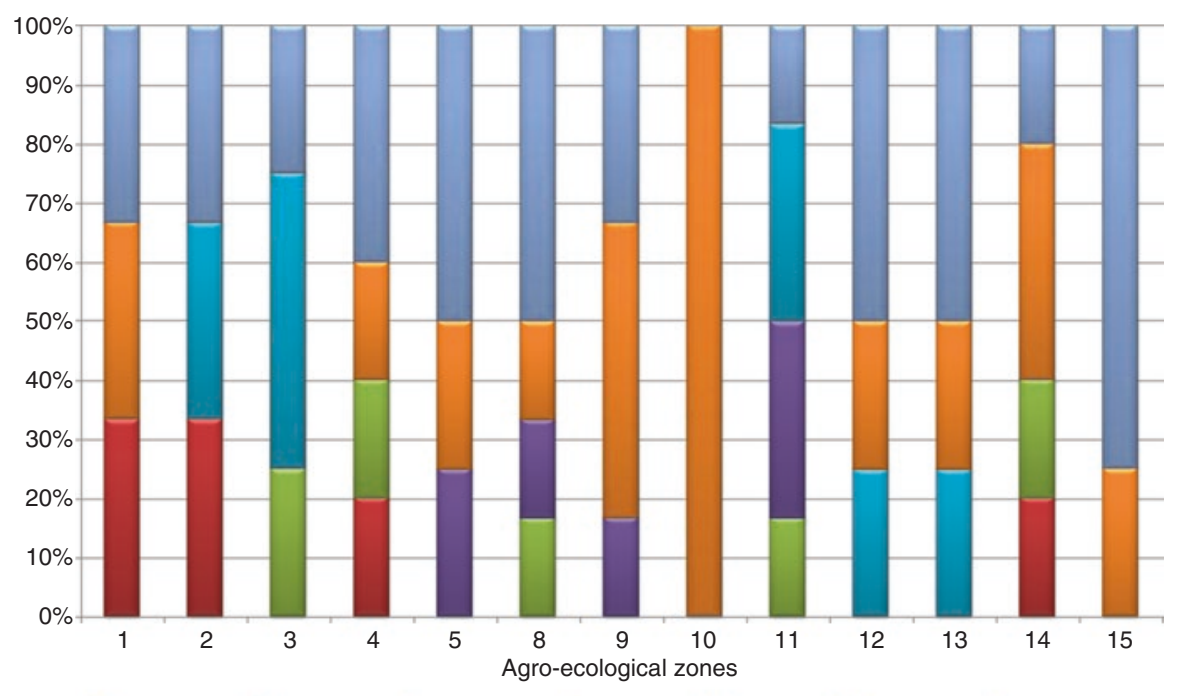

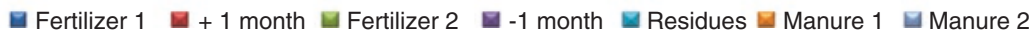

Fig. 11 Composition of mini-max adaptation strategies across agro-ecological zones (From Cervigni et al. 2013) 
Table 3 Applying mini-max rainfed adaptation options by year and climate model

\begin{tabular}{l|l|l|l|l|l|l}
\hline & \multicolumn{2}{l}{ l2020 } & \multicolumn{2}{l}{2050} & \\
\hline Crops & NCAR & GFDL & RCM & NCAR & GFDL & RCM \\
\hline Cassava & 0.00 & 0.00 & 0.22 & 0.00 & 0.23 & 2.06 \\
\hline Maize & 0.07 & 0.33 & 0.18 & 3.84 & 4.05 & 4.05 \\
\hline Millet & 0.00 & 0.00 & 0.27 & 3.01 & 3.16 & 3.16 \\
\hline Rice & 0.17 & 0.10 & 0.13 & 2.29 & 2.63 & 2.63 \\
\hline Sorghum & 0.36 & 0.34 & 0.29 & 4.01 & 4.42 & 4.42 \\
\hline Yams & 0.00 & 0.00 & 0.02 & 0.00 & 1.66 & 1.66 \\
\hline Total & 0.59 & 0.77 & 1.11 & 13.15 & 16.15 & 17.98 \\
\hline
\end{tabular}

Source: Cervigni et al. (2013)

In hectares and millions

Table 4 Production gap eliminated by mini-max rainfed options, by year and climate model

\begin{tabular}{l|l|l|l|l|l|l}
\hline & \multicolumn{5}{l}{} & \multicolumn{5}{l}{} & 2050 & \\
\hline Crops & NCAR & GFDL & RCM & NCAR & GFDL & RCM \\
\hline Cassava & n.a. & n.a. & 100 & n.a. & 100 & 92.2 \\
\hline Maize & 100 & 100 & 100 & 100 & 99.9 & 99.1 \\
\hline Millet & n.a. & n.a. & 95.1 & 100 & 82.6 & 78.3 \\
\hline Rice & 100 & 100 & 100 & 100 & 89.2 & 89.0 \\
\hline Sorghum & 100 & 100 & 100 & 100 & 94.0 & 93.9 \\
\hline Yams & n.a. & n.a. & 100 & n.a. & 97.4 & 92.3 \\
\hline
\end{tabular}

Source: Cervigni et al. (2013)

In percent

Table 5 Area of adaptation application by climate model

\begin{tabular}{l|l|l|l|r|r|r}
\hline & \multicolumn{3}{|l|}{2020} & \multicolumn{2}{l}{2050} \\
\hline Areas & NCAR & GFDL & RCM & NCAR & GFDL & RCM \\
\hline Farm practices in rain-fed areas & 0.59 & 0.77 & 1.11 & 14.26 & 16.15 & 17.98 \\
\hline Additional irrigation & 0.00 & 0.00 & 0.02 & 0.00 & 1.49 & 1.67 \\
\hline Total & 0.59 & 0.77 & 1.13 & 14.26 & 17.65 & 19.65 \\
\hline
\end{tabular}

Source: Cervigni et al. (2013)

In hectares and millions

Table 6 Aggregate costs and benefits of adaptation

\begin{tabular}{l|c|c|c}
\hline Variables & NCAR & GDFL & RCM \\
\hline GDP loss induced by climate change in 2050 & $2.9 \%$ & $3.6 \%$ & $4.5 \%$ \\
\hline GDP loss induced by adaptation in 2050: & $2.3 \%$ & $2.6 \%$ & $2.3 \%$ \\
\hline Low unit cost case & $15.5 \%$ & $14.3 \%$ & $12.7 \%$ \\
\hline High unit cost case & 1.26 & 1.38 & 1.96 \\
\hline Benefit cost ratio: & 0.19 & 0.25 & 0.35 \\
\hline$\quad$ Low unit cost case & &
\end{tabular}

Source: Cervigni et al. (2013) 
is no longer attractive, with the opportunity cost of capital diverted to adaptation far exceeding the benefit in terms of recovered production. The benefit-cost ratio is consistently less than 1 under all climate scenarios. These findings underscore the importance of supporting adaptation with measures to control the unit costs of investments in irrigation and sustainable land management practices, which appear to be consistently quite higher in Nigeria than in comparator countries in Africa.

\subsubsection{Robust Decision Making Approach for Irrigation Infrastructure}

The impact of adapting the design of reservoir or irrigation area to a wetter or dryer climate is quantified by calculating the avoided regrets. The regrets of using historical climate as a basis for planning and design of irrigation are typically between $10 \%$ (storage optimization, minimum average regrets) and 40\% (irrigated area optimization, minimum maximum regrets) of the investment cost. Results of the analysis show that these regrets can be greatly reduced by optimizing the design of irrigation schemes. On average, the regrets decrease 30-50\% depending on the type of optimization. Moreover, the results vary greatly among case studies, with up to $90 \%$ of the regrets that can be avoided in some locations.

Different classes of avoided regrets were defined based on their value compared to the investment cost. Optimizing the design has a high (low) impact if the avoided regrets exceed 20\% (are less than 5\%) of the investment cost, while the impact is moderate if the avoided regrets are between $5 \%$ and $20 \%$ of the investment cost. Results show that, in about half of the case studies, taking into account climate change in the design has a moderate to high impact, whichever optimization method is considered. Results obtained by optimizing the storage and the irrigated area optimization are illustrated on maps in Figs. 12 and 13.

The reduction in regrets exceeded $50 \%$ of the investment cost in two case studies in the northern part of the country. In these areas, the climate is projected to be much wetter than the historical scenario for all the perturbed models, as shown by the mean annual runoff and the storage-yield curves. Therefore, there is a strong incentive to build smaller dams to irrigate a given area (or larger irrigated area for a given storage). Nevertheless, these results should be taken with caution because of the significant uncertainties in climate models and the hydrological model, and should be completed with additional ensemble members (e.g. emission scenarios, climate models, hydrological model parameterization).

\section{Conclusions and Recommendations}

The results of this analysis indicate that in Nigeria the significance of climate shifts will increase in the medium term (2036-2065) compared to the short term (20062035). On average, temperatures in Nigeria will rise from 1 to $2{ }^{\circ} \mathrm{C}$, with the north more affected than the south. Projected changes in the amount and seasonal 


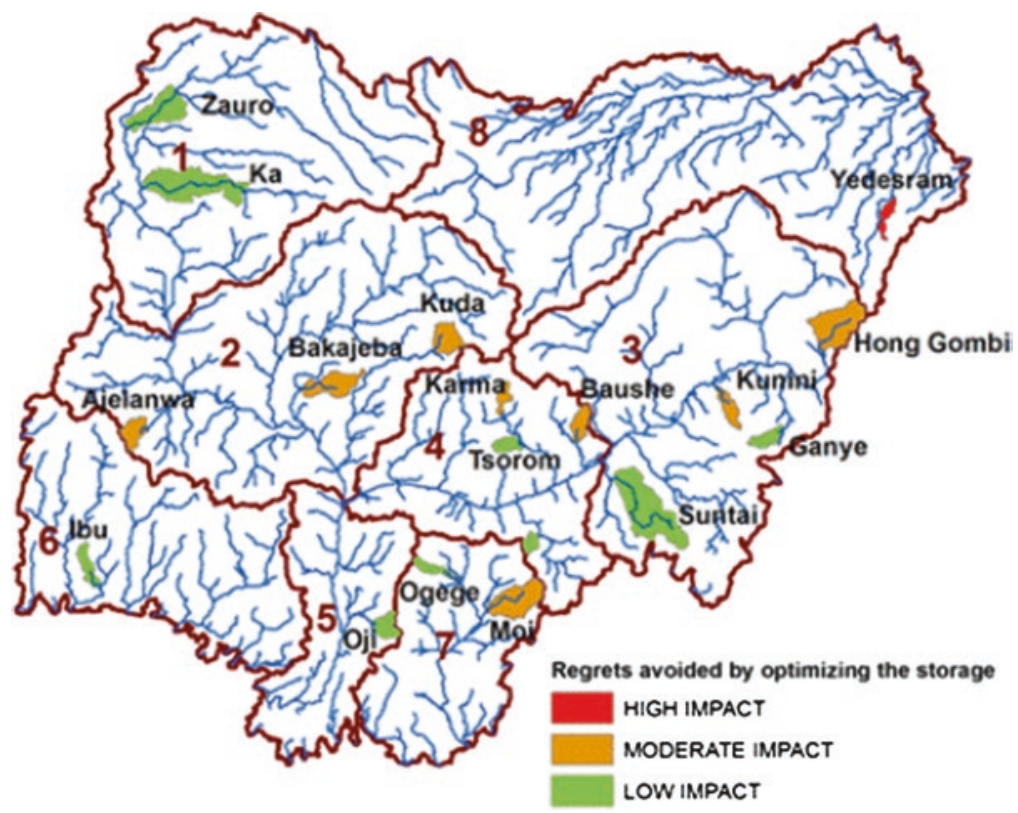

Fig. 12 Regrets avoided by optimizing the storage (From Cervigni et al. 2013). Note: Low impact: decrease in regrets is less than 5\% of the investment cost; moderate impact: between 5\% and 20\%; high impact: more than $20 \%$

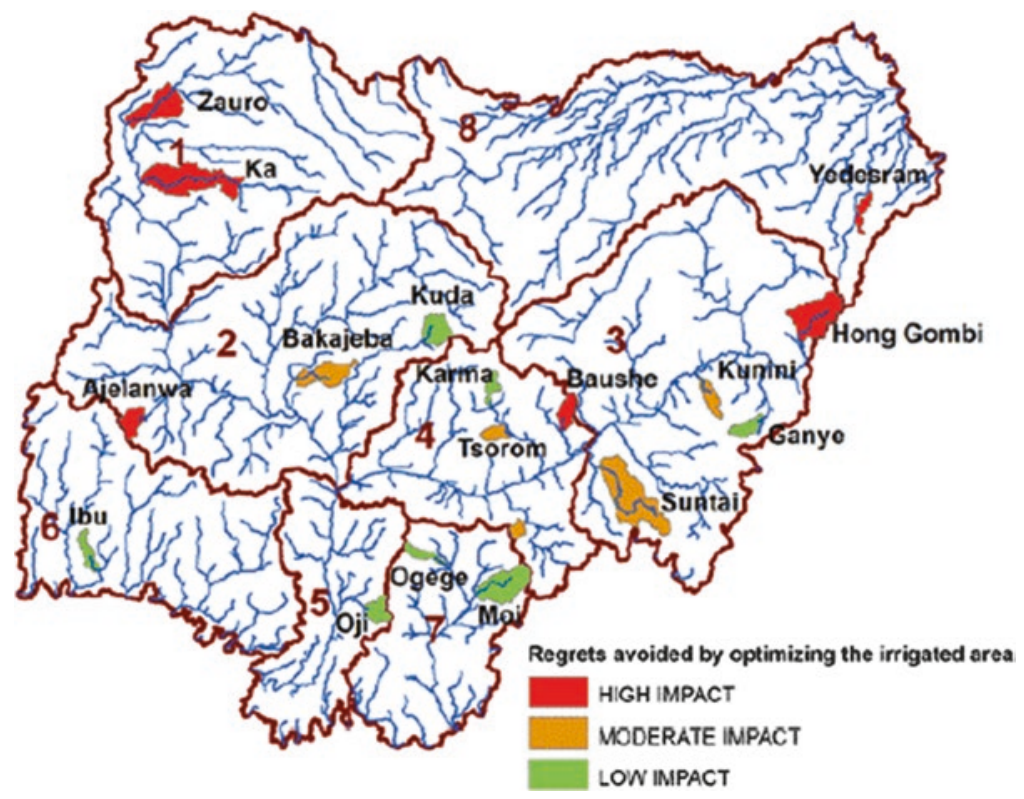

Fig. 13 Regrets avoided by optimizing the irrigated area (From Cervigni et al. 2013). Note: Low impact: decrease in regrets is less than $5 \%$ of the investment cost; moderate impact: between $5 \%$ and $20 \%$; high impact: more than $20 \%$ 
distribution of rainfall are quite uncertain, with no clear agreement among climate models on whether rainfall would rise or fall.

The combination of changes in temperature and precipitation shows biophysical impacts that can have significant consequences for the agriculture and related water sector. The likely negative impacts of climate change on rainfed agriculture and the increased uncertainty about water resources available in the future make it essential to consider climate change into agricultural sector planning.

Indeed agriculture will mainly be affected by loss of yields for the main crops (cassava, millet, yam, maize, sorghum, and rice), even if precipitation increases in several parts of the country. The effects are fairly clear in the longer term but somehow more ambiguous in the shorter term (2020) when, according to more than half of the climate models, cassava, and perhaps other crops, might actually experience an increase in productivity.

The projected decline in rainfed yields along with projected rises in temperature might ultimately reduce food security. It is projected that half of Nigeria's agroecological zones will be food insecure by 2020 and $75 \%$ by 2050 unless their diminishing local food production is complemented by improved in-country trade or more imports.

Impacts on water resources are more uncertain, but it looks very likely that availability of water for storage and use will be different from the past. In particular, our analysis suggests that, by 2050 , in only $23 \%$ of the country the hydrological regime will remain stable. In the rest of the country, the hydrology of the future will be very different than today, with $50 \%$ of the country expected to have higher runoff than the historical average, $10 \%$ of the country projected to be exposed to drier conditions, and $33 \%$ of total land area will be uncertain as climate models disagree so much that is difficult to define where runoff will increase or decrease.

The decline in crop yields will have significant consequences also for the national economy, by 2050 reducing GDP (compared to the no-climate change scenario) by up to $4.5 \%$. Climate change is also projected to increase net import of various crops, particularly rice and other cereals.

The major policy implication of our analysis is that ignoring the effects of climate change in the design of agriculture policies, programs and projects would have dire consequences on the sector's development prospects, and indeed on the country's overall growth. At the same time, because of large uncertainties on the magnitude, speed and, in the case of precipitation, even direction of change, there is no silver bullet to consider in the design of climate change adaptation interventions. In fact, selecting the wrong adaptation response to climate change may have costs as large as not adapting at all. In the case of the rainfed agriculture, the adoption of certain adaptation technologies (e.g. the shift in sowing date) may turn out be illsuited for some crops or agro-ecological regions, and result in a net decline in yields, rather than reducing climate change impacts. Similarly, development of irrigation schemes may lead to wrong-sizing of the amount of storage or irrigated area, both if climate change is ignored, and if a single scenario of climate change is arbitrarily selected (instead of considering the full range of possible outcomes). 
Admittedly, addressing head-on the challenge of uncertainty in designing adaptation responses to climate change requires investments in developing the human and institutional capacity required to assess the full spectrum of development outcomes of any given project. In that sense, there is a trade-off between rapidity (and political expediency) of adaptation response, and their longer term effectiveness and ability to minimize risks and regrets. It is easier to come up with a package of interventions that might only look at one end, rather than the full spectrum of possible climate rather outcomes; and it may put the country in a favorable position to gain access to bilateral and multilateral sources of climate finance. However, our analysis suggests that there may be considerable risks at stake, both for the country (which will not achieve the intended development benefits); and for the international donor community, which may not get the expected adaptation value for taxpayer money.

Our analysis suggests there is a wide range of land and water management practices that can offset or even reverse the effects of climate change on crops, and can do so in a robust way, i.e. improving yields, compared to the no-adaptation case, over a wide range of future climate scenarios. These practices include elements of conservation agriculture (e.g., integrated soil fertility management, water harvesting, and agroforestry). Other options are shifts in sowing/planting dates, crop rotation, minimum or no tillage, and restoration of degraded pasture.

A combination of robust sustainable land management practices for 14-18 million hectares (ha) of rainfed areas and 1.5-1.7 million additional irrigated ha might fully offset medium-term climate change impacts on agriculture. At low unit costs, this adaptation package has a benefit-cost ratio exceeding 1 in all climate scenarios considered.

Similarly, on irrigation, application of a robust decision making approach can assist in building climate resilience into investments. Testing the use of the approach on to 18 planned irrigation schemes, this work finds that the regrets for not including climate change in the design can be as high as $40 \%$ of investment costs; and that by selecting the investment strategy that minimizes regrets across multiple climate outcomes, they can be reduced by $30-50 \%$ on average, and up to $90 \%$ in some locations.

Finally, an important challenge for policy is that action on adaptation may be perceived as having benefits too differed in time (i.e. too far past the time of action). Nevertheless, there are at least three reasons why the Government may act now to deal with climate change. First, many actions that will strengthen longer-term climate resilience will also help reduce the vulnerability to current climate swings. Second, investment decisions that will be taken in the near future on long-lived infrastructure, such as irrigation schemes, will determine how resilient these investments will be to the harsher climate of the future. To avoid locking the sector in a state of future climate vulnerability, it is essential to carefully evaluate the implications of alternative planning and design options overs a wide range of future climate scenarios. Third, building the knowledge, capacity, institutions and policies needed to deal with the climate of the future takes time. The longer Nigeria delays action, the less time it will have to get ready, and the more it will have to resort to reactive practices rather than prevention. 
The actions that Nigeria could consider to enhance its overall ability to plan and implement climate-resilient development could be organized around the three areas:

1. consolidate and harmonize policies and legislation to effectively integrate climate change considerations into sector planning and development;

2. develop practical knowledge on climate resilience practices and technologies to define and prioritize, across space and crops, opportunities for adopting "triplewin" agricultural options (higher yields, higher climate resilience, reduced carbon emissions) and solutions on the ground that farmers can adopt;

3. promote investments and resource mobilization.

Enhancing the climate resilience of the economy is likely to be a major undertaking that no individual institution can accomplish on its own. Considering that States and LGAs control a large share of public spending in many of the highly climate vulnerable sectors, the Federal Government may want to establish strategic partnerships with the States to optimize the planning and implementation of adaptation efforts across levels of government and budgetary lines.

\section{References}

Adejuwon JO (2005) Food crop production in Nigeria. I. Present effects of climate variability. Clim Res 30:53-60.

Buishand TA, and Lenderink G (2004) Estimation of Future Discharges of the River Rhine in the SWURVE Project. KNMI, Technical Report, Royal Netherlands Meteorological Institute, De Bilt, Netherlands.

Cervigni R, Valentini R, Santini M (2013) Toward climate-resilient development in Nigeria. Directions in development. World Bank, Washington.

Challinor AJ, Ewert F, Arnold S et al. (2009) Crops and climate change: progress, trends, and challenges in simulating impacts and informing adaptation. J Exp Bot. 60(10):2775-2789.

Daron J. (2015) Challenges in using a Robust Decision Making approach to guide climate change adaptation in South Africa. Climatic Change 132:459-473. DOI 10.1007/s10584-014-1242-9.

FAO (2005) Irrigation in Africa in figures: AQUASTAT Survey-2005. FAO Water Report 29 (with CD ROM). Rome.

FAO (2016) AQUASTAT website. Food and Agriculture Organization of the United Nations (FAO). Website accessed on [2016/05/07].

FAO (2015) FAOSTAT.. http://faostat.fao.org/

Hoogenboom G, Jones JW, Wilkens PW, Porter CH et al. (2012) Decision Support System for Agrotechnology Transfer (DSSAT) version 4.5. University of Hawaii, Honolulu.

ICS-Nigeria, Information and Communication Support for Agricultural Growth in Nigeria. http:// www.icsnigeria.org. Accessed 23 June 2011.

IPCC (2014) Summary for policymakers. In: Climate Change 2014: Impacts, Adaptation, and Vulnerability. Part A: Global and Sectoral Aspects. Contribution of Working Group II to the Fifth Assessment Report of the Intergovernmental Panel on Climate Change [Field CB, Barros VR, Dokken DJ, Mach KJ, Mastrandrea MD, Bilir TE, Chatterjee M, Ebi KL, Estrada YO, Genova RC, Girma B, Kissel ES, Levy AN, MacCracken S, Mastrandrea PR, and White LL (eds.)]. Cambridge University Press, Cambridge, United Kingdom and New York, NY, USA, pp. $1-32$.

JICA (1995) The Study on the National Water Master Plan. Sector Report Vol 2. Report prepared for the Federal Ministry of Water Resources and Rural Development. Nigeria. 
Jones JW, Hoogenboom G, Porter CH et al. (2003) The DSSATcropping system model. Eur J Agron 18:235-265.

Lebel T., Ali A. (2009) Recent trends in the Central and Western Sahel rainfall regime (19902007). Journal of Hydrology, 375:52-64.

Lempert RJ, Nakicenovic N, Sarewitz D, Schlesinger M (2004) Characterizing Climate-Change Uncertainties for Decision-Makers. An Editorial Essay. Climatic Change, 65(1):1-9.

Lempert RJ, Groves DG, Popper SW, Bankes SC (2006) A General, Analytic Method for Generating Robust Strategies and Narrative Scenarios. Management Science, 52(4):514-528.

Lempert RJ, Collins MT (2007) Managing the Risk of Uncertain Threshold Responses: Comparison of Robust, Optimum and Precautionary Approaches. Risk Analysis 27(4):1009-1026.

Lobell DB, Burke MB, Tebaldi C et al. (2008) Prioritizing climate change adaptation needs for food security in 2030. Science 319:607-610.

Lobell DB, Burke MB (2010) On the use of statistical models to predict crop yield responses to climate change. Agric. Forest Meteorol. 150:1443-1452.

Mereu V, Carboni G, Gallo A, Cervigni R, Spano D (2015) Impact of climate change on staple food crop production in Nigeria. Climatic Change 132(2):321-336.

Müller C, CramerW, Hare WL et al (2011) Climate change risks for African agriculture. Proc Natl Acad Sci USA 108:4313-4315.

NPC - National Planning Commission (2004) Meeting everyone"s needs: National Economic Empowerment and Development Strategy. Abuja, Nigeria: National Planning Commission.

NSSP - Nigeria Strategy Support Program (2010) Background Paper No. NSSP 011, January 2010. Available at: http://nssp.ifpri.info/2010/02/09/\%e2\%80\%9coptions-for-enhancing-agricultural-productivity-in-nigeria\%e2\%80\%9d/. [Accessed on 08 May 2016].

Odekunle TO (2004) Rainfall and the length of the growing season in Nigeria. Int J Climatol 24:467-79.

Parry M, Rosenzweig C, Iglesias A, Livermore M et al (2004) Effects of climate change on global food production under SRES emissions and socio-economic scenarios. Glob Environ Chang 14:53-67.

Rockel B, Will A, Hense A (2008) The regional Climate Model COSMO-CLM (CCLM). Meteorologische Zeitschrift 17:347-348.

Rosenzweig C, Jones JW, Hatfield JL et al (2013) The Agricultural Model Intercomparison and Improvement Project (AgMIP): protocols and pilot studies. Agric For Meteorol 170:166-182.

Roudier P, Sultan B, Quirion P, Berg A (2011) The impact of future climate change on West African crop yields: what does the recent literature say? Global Environmental Change 21:1073-1083.

Schlenker W, Lobell DB (2010) Robust negative impacts of climate change on African agriculture. Environ Res Lett, 5:1-8.

Schuol J, Abbaspour KC (2006) Calibration and uncertainty issues of a hydrological model (SWAT) applied to West Africa. Advances in Geosciences, 9:137-143.

Schuol J, Abbaspour KC, Sarinivasan R, Yang H (2008) Estimation of freshwater availability in the West African Sub-continent using the SWAT hydrologic model. J Hydrol, 352:30-49.

Scoccimarro E, Gualdi S, Bellucci A et al (2011) Effects of tropical cyclones on ocean heat transport in a high resolution coupled general circulation model. Journal of Climate 24:4368-4384.

Semenov MA, Porter JR (1995) Climatic variability and the modelling of crop yields. Agric For Meteorol, 73:265-283.

Seo N, Mendelsohn R, Dinar A, Hassan R, Kurukulasuriya P. (2008a) A Ricardian Analysis of the Distribution of Climate Change Impacts on Agriculture Across Agro-Ecological Zones in Africa. World Bank Policy Research Working Paper 4599.

Seo N, Mendelsohn R, Dinar A, Kurukulasuriya P, Hassan R (2008b) Differential Adaptation Strategies to Climate Change in African Cropland by Agro-Ecological Zones. World Bank Policy Research Working Paper 4600.

Seo N, Mendelsohn R, Dinar A, Kulukulasuriya P., Hassan R (2008c) Long-Term Differential Adaptation by Selection of Farm Types Across Agro Ecological Zones in Africa. World Bank Policy Research Working Paper 4602. 
Thomas HA, Burden RP (1963) Operations research in water quality management. Division of Engineering and Applied Physics, Harvard University.

Thornton PK, Jones PG, Alagarswamy G, Andresen J (2009) Spatial variation of crop yield response to climate change in East Africa. Glob Environ Chang 19:54-65.

USAID MARKETS (2009a) Package of practices for sorghum production.. http://www.nigeriamarkets.org/files/Sorghum_Pop_English_July_2009.pdf. Accessed 01 May 2011.

USAID MARKETS (2009b) Package of practices for rice production.. http://www.nigeriamarkets. org/files/Rice_Pop_English_June_2009.pdf. Accessed 13 December 2011.

USAID MARKETS (2010) Package of practices for maize production.. http://www.nigeriamarkets.org/files/Maize_Pop_2010_English_final.pdf. Accessed 01 May 2011.

Webber H, Gaiser T, Ewert F (2014) What role can crop models play in supporting climate change adaptation decisions to enhance food security in Sub-Saharan Africa? Agricultural Systems 127:161-177.

Wilby RL, Dessai S (2010) Robust adaptation to climate change. Weather, 65(7):180-185.

World Bank (2010) Africa Infrastructure: a time for transformation. Washington DC. World Bank. Yakubu MM, Akanegbu BN (2015) The impact of international trade on economic growth in Nigeria: 1981 - 2012. European Journal of Business, Economics and Accountancy, 3(6): 26-36.

Open Access This chapter is distributed under the terms of the Creative Commons AttributionNonCommercial-ShareAlike 3.0 IGO license (https://creativecommons.org/licenses/by-nc-sa/3.0/ igo/), which permits any noncommercial use, duplication, adaptation, distribution, and reproduction in any medium or format, as long as you give appropriate credit to the Food and Agriculture Organization of the United Nations (FAO), provide a link to the Creative Commons license and indicate if changes were made. If you remix, transform, or build upon this book or a part thereof, you must distribute your contributions under the same license as the original. Any dispute related to the use of the works of the FAO that cannot be settled amicably shall be submitted to arbitration pursuant to the UNCITRAL rules. The use of the FAO's name for any purpose other than for attribution, and the use of the FAO's logo, shall be subject to a separate written license agreement between the FAO and the user and is not authorized as part of this CC-IGO license. Note that the link provided above includes additional terms and conditions of the license.

The images or other third party material in this chapter are included in the chapter's Creative Commons license, unless indicated otherwise in a credit line to the material. If material is not included in the chapter's Creative Commons license and your intended use is not permitted by statutory regulation or exceeds the permitted use, you will need to obtain permission directly from the copyright holder.

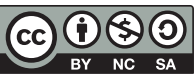

